\title{
The influence of atrial fibrillation on the levels of NT-proBNP versus GDF-15 in patients with heart failure
}

\author{
Bernadet T. Santema ${ }^{1} \cdot$ Michelle M. Y. Chan $^{2}$. Jasper Tromp ${ }^{1,2} \cdot$ Martin Dokter $^{1} \cdot$ Haye H. van der Wal ${ }^{1}$. \\ Johanna E. Emmens ${ }^{1}$. Janny Takens ${ }^{1}$. Nilesh J. Samani ${ }^{3,4} \cdot$ Leong L. $\mathrm{Ng}^{3,4}$. Chim C. Lang ${ }^{5}$. Peter van der Meer ${ }^{1}$. \\ Jozine M. ter Maaten ${ }^{1} \cdot$ Kevin Damman $^{1} \cdot$ Kenneth Dickstein ${ }^{6,7} \cdot$ John G. Cleland $^{8,9} \cdot$ Faiez Zannad $^{10}$. \\ Stefan D. Anker ${ }^{11}$. Marco Metra ${ }^{12}$ • Pim van der Harst ${ }^{1} \cdot$ Rudolf A. de Boer $^{1}$ • Dirk J. van Veldhuisen ${ }^{1}$. \\ Michiel Rienstra ${ }^{1} \cdot$ Carolyn S. P. Lam ${ }^{1,2} \cdot$ Adriaan A. Voors $^{1}$ (1)
}

Received: 12 March 2019 / Accepted: 19 June 2019 / Published online: 1 July 2019

(c) The Author(s) 2019

\begin{abstract}
Background In heart failure (HF), levels of NT-proBNP are influenced by the presence of concomitant atrial fibrillation (AF), making it difficult to distinguish between HF versus AF in patients with raised NT-proBNP. It is unknown whether levels of GDF-15 are also influenced by AF in patients with HF. In this study we compared the plasma levels of NT-proBNP versus GDF-15 in patients with $\mathrm{HF}$ in AF versus sinus rhythm (SR).

Methods In a post hoc analysis of the index cohort of BIOSTAT-CHF $(n=2516)$, we studied patients with HF categorized into three groups: (1) AF at baseline $(n=733)$, (2) SR at baseline with a history of AF $(n=183)$, and (3) SR at baseline and no history of AF $(n=1025)$. The findings were validated in the validation cohort of BIOSTAT-CHF $(n=1738)$.

Results Plasma NT-proBNP levels of patients who had AF at baseline were higher than those of patients in SR (both with and without a history of AF), even after multivariable adjustment (3417 [25th-75th percentile 1897-6486] versus 1788 [682-3870], adjusted $p<0.001$, versus $2231 \mathrm{pg} / \mathrm{mL}$ [902-5270], adjusted $p<0.001$ ). In contrast, after adjusting for clinical confounders, the levels of GDF-15 were comparable between the three groups (3179 [2062-5253] versus 2545 [1686-4337], adjusted $p=0.36$, versus 2294 [1471-3855] pg/mL, adjusted $p=0.08$ ). Similar patterns of both NT-proBNP and GDF-15 were found in the validation cohort.
\end{abstract}

Electronic supplementary material The online version of this article (https://doi.org/10.1007/s00392-019-01513-y) contains supplementary material, which is available to authorized users.

Adriaan A. Voors

a.a.voors@umcg.nl

1 Department of Cardiology, University of Groningen, University Medical Centre Groningen, Hanzeplein 1, 9713 GZ Groningen, The Netherlands

2 Department of Cardiology, National Heart Centre Singapore, Singapore Duke-NUS Graduate Medical School, Singapore, Singapore

3 Department of Cardiovascular Sciences, University of Leicester, Groby Road, Leicester LE3 9QP, UK

4 NIHR Leicester Biomedical Research Centre, Glenfield Hospital, Groby Road, Leicester LE3 9QP, UK

5 Division of Molecular and Clinical Medicine, School of Medicine University of Dundee, Ninewells Hospital and Medical School, Dundee DD1 9SY, UK

6 University of Bergen, Bergen, Norway
7 Stavanger University Hospital, Stavanger, Norway

$8 \quad$ National Heart \& Lung Institute, Royal Brompton \& Harefield Hospitals, Imperial College, Sydney St, Chelsea, London SW3 6NP, UK

9 Robertson Institute of Biostatistics and Clinical Trials Unit, University of Glasgow, University Avenue, Glasgow G12 8QQ, UK

10 Inserm CIC 1433, Université de Lorrain, CHU de Nancy, Nancy, France

11 Department of Cardiology (CVK), and Berlin Institute of Health Center for Regenerative Therapies (BCRT), German Centre for Cardiovascular Research (DZHK) partner site Berlin, Charité Universitätsmedizin, Berlin, Germany

12 Department of Medical and Surgical Specialties, Radiological Sciences and Public Health, Institute of Cardiology, University of Brescia, Brescia, Italy 
Conclusion These data show that in patients with HF, NT-proBNP is significantly influenced by underlying AF at time of measurement and not by previous episodes of AF, whereas the levels of GDF-15 are not influenced by the presence of AF. Therefore, GDF-15 might have additive value combined with NT-proBNP in the assessment of patients with HF and concomitant AF.

\section{Graphic abstract}

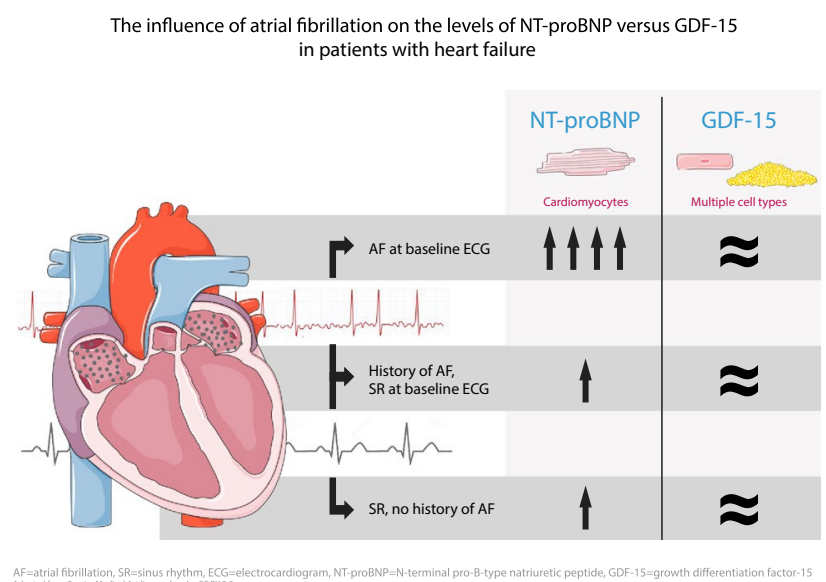

Keywords Atrial fibrillation $\cdot$ Heart failure $\cdot$ Biomarkers $\cdot$ Natriuretic peptides $\cdot$ GDF-15

\begin{tabular}{|c|c|}
\hline Abbreviations & \\
\hline $\mathrm{AF}$ & Atrial fibrillation \\
\hline BIOSTAT-CHF & $\begin{array}{l}\text { The BIOlogy Study to Tailored Treat- } \\
\text { ment in Chronic Heart Failure }\end{array}$ \\
\hline ECG & Electrocardiogram \\
\hline GDF-15 & Growth differentiation factor- 15 \\
\hline $\mathrm{HF}$ & Heart failure \\
\hline LVEF & Left ventricular ejection fraction \\
\hline NT-proBNP & $\begin{array}{l}\mathrm{N} \text {-terminal pro-B-type natriuretic } \\
\text { peptide }\end{array}$ \\
\hline SR & Sinus rhythm \\
\hline
\end{tabular}

\section{Introduction}

$\mathrm{N}$-terminal pro-B-type natriuretic peptide (NT-proBNP) plays an important role in the diagnosis and prognosis of heart failure (HF) [1, 2]. For the diagnosis of HF, this marker is known for its high sensitivity, but lower specificity, which makes NT-proBNP especially helpful to rule out HF [3]. Several other conditions, such as renal failure, pulmonary embolism and atrial fibrillation (AF), are also known to further elevate NT-proBNP levels in patients with concomitant $\mathrm{HF}$. AF in this regards is particularly important because it is highly prevalent among patients with HF regardless of ejection fraction, and mimics the symptoms (breathlessness) and signs (left atrial enlargement) of HF. Therefore, it is often unclear how elevated NT-proBNP levels in patients with HF and AF should be interpreted, since there are several potential explanations for these elevated levels [4-6]. First, NTproBNP elevations may be directly related to the immediate hemodynamic alterations during the actual episode of AF [7]. Secondly, elevated levels of NT-proBNP may be related to the chronic structural or functional cardiac remodeling as a result of sustained episodes of AF, or in the third place, just reflect that patients with AF have more advanced HF. In most contemporary clinical HF trials, different NT-proBNP thresholds are being used for inclusion of patients with and without $\mathrm{AF}$, often without further differentiation between patients who only have a history of AF, and those who have $\mathrm{AF}$ at time of enrollment.

In the past years, many markers have been shown to have strong prognostic value in HF, of which growth differentiation factor-15 (GDF-15) is amongst the best established ones [8-11]. GDF-15 is a protein belonging to the transforming growth factor-beta superfamily, and has a role in inflammatory and apoptotic cell processes, and is produced by multiple organs, including the heart [12-14]. It is, however, unknown how the plasma levels of GDF-15 are influenced by underlying AF in patients with HF. The search for a biomarker that is less influenced by underlying AF than NTproBNP is, could be of help in the assessment of patients with both $\mathrm{HF}$ and $\mathrm{AF}$.

To investigate whether the levels of GDF-15 are similarly elevated as NT-proBNP by concomitant AF in patients with HF, we performed a post hoc analysis of these two 
biomarkers in The BIOlogy Study to Tailored Treatment in Chronic Heart Failure (BIOSTAT-CHF) [15].

\section{Methods}

\section{Patient population and definitions}

In the multinational, prospective, observational index cohort of BIOSTAT-CHF, 2516 patients with new-onset or worsening signs and/or symptoms of HF from 11 European countries were included between 2010 and 2012 [15]. Patients had to have evidence of cardiac dysfunction documented either by left ventricular ejection fraction (LVEF) of $\leq 40 \%$ or plasma concentrations of NT-proBNP $>2000 \mathrm{pg} / \mathrm{mL}$ (this cutoff was the same for patients in sinus rhythm [SR] and $\mathrm{AF})$. A comparable validation cohort of BIOSTAT-CHF included another 1738 patients from six centers in Scotland between 2010 and 2014, who had to have a previously documented admission for HF. No additional LVEF or NTproBNP was used for the validation cohort, which resulted in a higher percentage of patients with heart failure with preserved ejection fraction (HFpEF, 34\% in the validation cohort versus $7 \%$ in the index cohort).

In both cohorts, a standard 12-lead electrocardiogram (ECG) was performed at baseline, generally on the same day as the time of blood draw for biomarker measurements (median difference of 0 days with 25 th-75th percentile [Q1-Q3] from -2 to +2 days. Patients were categorized into three groups based on history and baseline ECG: (1) AF at baseline, (2) history of AF but in SR at baseline, and (3) SR at baseline and no previously documented episode of AF. Patients with a rhythm other than SR or AF on the baseline ECG were excluded (pacemaker rhythm, $n=283$, and unknown rhythm, $n=55$ ) [16]. The study was conducted according to the Declaration of Helsinki, approved by the medical ethics committees of participating centers, and all patients provided informed consent.

\section{Biomarkers}

Measurement of NT-proBNP and GDF-15 was performed at baseline. The levels of NT-proBNP and GDF-15 were measured using electrochemiluminescence on a cobas e 411 analyzer, using standard methods (Roche Diagnostics GmbH, Mannheim, Germany) [17, 18].

\section{Statistical analyses}

Normally distributed variables were displayed as mean with standard deviation, non-normally distributed variables as median with 25 th-75th percentile, and categorical variables as numbers with percentages. Group differences were assessed with $t$ tests and one-way analysis of variance for normally distributed variables, Kruskal-Wallis and Mann-Whitney $U$ tests for non-normally distributed continuous variables, and $\chi^{2}$ tests for categorical variables. Multiple linear regression models were used to investigate the associations between NT-proBNP and GDF-15 and the three rhythm groups. Natural transformed biomarkers were used in the regression analyses. Potential and known confounders of the two biomarkers were included in the regression model, including age, sex, body mass index (BMI), LVEF, heart rate, renal disease [estimated glomerular filtration rate (eGFR) using the Chronic Kidney Disease Epidemiology Collaboration (CKD-EPI) formula], a previous myocardial infarction, diabetes mellitus, and the use of ACE-inhibitors/ ARBs and beta-blockers at baseline. To test which variables had the strongest association with elevated levels of NTproBNP and GDF-15, both biomarkers were analyzed as a dependent variable in uni- and multi-variable linear regression analysis. The multivariable models were built with all variables with $p<0.10$ in the univariable analysis, after which backward elimination was performed. Variables that had the strongest associations in both the index and validation cohort were displayed in the final multivariable model. A $p$ value of $<0.1$ was considered significant for testing interactions. $p$ values of $<0.05$ were considered statistically significant in all other analyses. All analyses were conducted with $\mathrm{R}$ version 3.5.2 (R Foundation for Statistical Computing, Vienna, Austria).

\section{Results}

\section{Index cohort}

A total of 1941 patients with HF were studied, of whom 733 patients had AF at baseline, 183 patients had a history of AF but were in SR at baseline, and 1025 had SR at baseline and no previously documented episode of AF. The characteristics of the patients within these three rhythm groups are summarized in Table 1. Main findings were that patients with $\mathrm{AF}$ at baseline were significantly older, had a higher BMI and higher heart rate, and less often had a previous myocardial infarction as compared with the two other groups who were in SR at baseline.

The plasma levels of NT-proBNP were significantly higher in patients who had AF at baseline, with a median of $3417 \mathrm{pg} / \mathrm{mL}$ (1897-6486), as compared with patients who were in SR at baseline; both those who had a history of AF $(1788 \mathrm{pg} / \mathrm{mL}$ [682-3870], $p<0.001)$ and those who never had AF before $(1588 \mathrm{pg} / \mathrm{mL}$ [902-5270], $p<0.001)$ (Table 1), also after multivariable adjustment (Table 2). In univariable analysis, the levels of GDF-15 were also highest 
Table 1 Baseline characteristics of the index cohort, stratified by heart rhythm

\begin{tabular}{|c|c|c|c|c|}
\hline Clinical characteristic & $\begin{array}{l}\mathrm{AF} \text { at baseline } \\
N=733(38 \%)\end{array}$ & $\begin{array}{l}\text { History of AF-SR at baseline } \\
N=183(9 \%)\end{array}$ & $\begin{array}{l}\text { Sinus rhythm } \\
N=1025(53 \%)\end{array}$ & $P$ for trend \\
\hline Age (years) & $76 \pm 10$ & $72 \pm 11$ & $70 \pm 13$ & $<0.001$ \\
\hline Women $(\%)$ & $182(25)$ & $51(28)$ & $301(29)$ & 0.110 \\
\hline BMI $\left(\mathrm{kg} / \mathrm{m}^{2}\right)$ & $28.5 \pm 5.6$ & $28.3 \pm 5.1$ & $27.5 \pm 5.5$ & 0.001 \\
\hline NYHA (\%) & & & & 0.010 \\
\hline $\mathrm{I} / \mathrm{II}$ & $202(28)$ & $68(37)$ & $331(32)$ & \\
\hline III & $233(36)$ & $37(23)$ & $270(31)$ & \\
\hline IV & $28(4)$ & $7(4)$ & $33(4)$ & \\
\hline LVEF, \% & $33 \pm 12$ & $33 \pm 11$ & $29 \pm 10$ & $<0.001$ \\
\hline Systolic blood pressure (mmHg) & $125 \pm 22$ & $126 \pm 24$ & $126 \pm 22$ & 0.780 \\
\hline Diastolic blood pressure $(\mathrm{mmHg})$ & $76 \pm 14$ & $75 \pm 16$ & $75 \pm 13$ & 0.188 \\
\hline Heart rate (beats/min) & $93 \pm 25$ & $73 \pm 16$ & $79 \pm 18$ & $<0.001$ \\
\hline \multicolumn{5}{|l|}{ History of $(\%)$} \\
\hline Myocardial infarction & $215(29)$ & $67(37)$ & $431(42)$ & $<0.001$ \\
\hline Stroke & $83(11)$ & $27(15)$ & $72(7)$ & $<0.001$ \\
\hline Hypertension & $470(64)$ & $118(65)$ & $623(61)$ & 0.300 \\
\hline Diabetes mellitus & $232(32)$ & $63(34)$ & $320(31)$ & 0.691 \\
\hline COPD & $133(18)$ & $46(25)$ & $150(15)$ & 0.001 \\
\hline \multicolumn{5}{|l|}{ Medication (\%) } \\
\hline ACE-inhibitors/ARBs & $504(69)$ & $135(74)$ & $770(75)$ & 0.012 \\
\hline Beta-blockers & $599(82)$ & $160(87)$ & $850(83)$ & 0.185 \\
\hline Loop diuretics & $732(100)$ & $183(100)$ & $1024(100)$ & 0.873 \\
\hline Amiodarone & $92(13)$ & $67(37)$ & $117(11)$ & $<0.001$ \\
\hline Digoxin & $282(39)$ & $21(12)$ & $72(7)$ & $<0.001$ \\
\hline Verapamil/diltiazem & $18(3)$ & $4(2)$ & $7(1)$ & 0.008 \\
\hline Class 1c antiarrhythmic drugs & $2(1)$ & $5(3)$ & $2(1)$ & $<0.001$ \\
\hline Ivabradine & $0(0)$ & $2(1)$ & $26(3)$ & $<0.001$ \\
\hline \multicolumn{5}{|l|}{ Laboratory data } \\
\hline eGFR & $58.0 \pm 21.8$ & $59.2 \pm 20.8$ & $66.0 \pm 23.4$ & $<0.001$ \\
\hline NT-proBNP (pg/mL) & $3417[1897,6486]$ & $1788[682,3870]$ & $2231[902,5270]$ & $<0.001$ \\
\hline GDF-15 (pg/mL) & $3197[2062,5253]$ & $2545[1686,4337]$ & $2294[1471,3855]$ & $<0.001$ \\
\hline
\end{tabular}

$A F$ atrial fibrillation, $S R$ sinus rhythm, $B M I$ body mass index, NYHA New York Heart Association, $L V E F$ left ventricular ejection fraction, $C O P D$ chronic obstructive pulmonary disease, $A C E$ angiotensin converting enzyme, $A R B$ angiotensin receptor blockers, $e G F R$ estimated glomerular filtration rate, $N T$-proBNP N-terminal pro-B-type natriuretic peptide, GDF15 growth differentiation factor 15

in patients with $\mathrm{AF}$ at baseline and lowest in patients who were in SR at baseline (Table 1), but after adjusting for clinical confounders, the levels of GDF-15 between patients with $\mathrm{AF}$ at baseline and those in SR with and without previous AF were comparable (Table 2).

\section{Validation cohort}

Baseline characteristics of the validation cohort were generally comparable to the index cohort of BIOSTAT-CHF (Supplementary Table 1). As discussed previously, a higher number of patients with HFpEF were included in the validation cohort, which resulted in a higher number of women, a higher LVEF, and lower levels of NT-proBNP in all three groups. Despite these differences in baseline characteristics, similar patterns of plasma levels of both NT-proBNP and GDF-15 were found in the validation cohort as compared to the index cohort. Patients with AF at baseline had a median NT-proBNP of $2105 \mathrm{pg} / \mathrm{mL}$ (1015-4472), which was significantly higher than those who had a history of AF but were in SR at baseline (1063 [440-4094], $p<0.001)$ and patients in SR who never had AF before (874 [314-2758]). The levels of GDF-15 were comparable among the three groups after multivariable adjustment (Table 2). No significant interactions between the biomarkers and the rhythm groups in heart failure with reduced ejection fraction (HFrEF) versus HFpEF were found in both the index and validation cohort. 
Table 2 Multivariable differences of the plasma levels of NT-proBNP and GDF-15 between the three rhythm groups in the index and validation cohort

\begin{tabular}{|c|c|c|c|c|c|}
\hline \multicolumn{6}{|l|}{ Index cohort } \\
\hline & NT-proBNP & & & GDF-15 & \\
\hline $\mathrm{AF}$ at baseline & \multirow{3}{*}{ f $p<0.001$} & \multirow{3}{*}{$p<0.001$} & $\mathrm{AF}$ at baseline & $7 \mathrm{NS}$ & \multirow{3}{*}{ NS } \\
\hline History of $\mathrm{AF}-\mathrm{SR}$ at baseline & & & History of $\mathrm{AF}-\mathrm{SR}$ at baseline & $5 \mathrm{NS}$ & \\
\hline Sinus rhythm & & & Sinus rhythm & & \\
\hline \multicolumn{6}{|l|}{ Validation cohort } \\
\hline & \multicolumn{2}{|l|}{ NT-proBNP } & & \multicolumn{2}{|l|}{ GDF-15 } \\
\hline $\mathrm{AF}$ at baseline & 1 & \multirow{3}{*}{ ] $\quad p<0.001$} & $\mathrm{AF}$ at baseline & & \multirow{3}{*}{ NS } \\
\hline History of AF-SR at baseline & $p=0.02$ & & History of AF-SR at baseline & NS & \\
\hline Sinus rhythm & & & Sinus rhythm & & \\
\hline
\end{tabular}

Adjusted for age, sex, body mass index, left ventricular ejection fraction, heart rate, estimated glomerular filtration rate, a previous myocardial infarction, diabetes mellitus, and the use of ACE-inhibitors/ARBs and beta-blockers at baseline

NT-proBNP N-terminal pro-B-type natriuretic peptide, GDF15 growth differentiation factor 15, NYHA New York Heart Association, BMI body mass index, $L V E F$ left ventricular ejection fraction, $e G F R$ estimated glomerular filtration rate, $N S$ non-significant

\section{Correlates of NT-proBNP versus GDF-15}

The multivariable models with the correlates of elevated levels of NT-proBNP and GDF-15 are presented in Table 3. AF at baseline was strongly associated with elevated levels of NT-proBNP in both the index and validation cohort. Other variables that were strongly associated with elevated levels of NT-proBNP were age, BMI, LVEF and eGFR. AF at baseline was not associated with higher levels of GDF-15 in the multivariable model. Variables that were strongly associated with higher levels of GDF-15 in both cohorts were age, systolic blood pressure, diabetes mellitus and eGFR.

\section{Discussion}

These data suggest that in patients with HF, after adjustment for clinical confounders, the levels of NT-proBNP, but not GDF-15, are significantly influenced by the presence of $\mathrm{AF}$ at time of measurement. GDF-15 is mainly produced in non-cardiac and peripheral tissues, such as endothelial cells and adipocytes, and we recently showed that the levels of GDF-15 in mice are 2- to 60-fold higher in the liver, lungs and kidney than in the cardiac muscle [19]. Therefore, this marker reflects changes in many organs, not just in the cardiac ventricles and atria, and might therefore be less likely to be load-dependent as compared with NT-proBNP. Since levels of GDF-15 are independent of the presence of AF in patients with HF, it may better reflect HF patients' overall clinical condition, including non-cardiac comorbidities [20].

Previous studies have shown that the levels of GDF-15 in $\mathrm{AF}$ patients without $\mathrm{HF}$ are fairly similar to the levels in community-dwelling elderly [21]. In the AF field, GDF15 is of increasing interest since this biomarker was the strongest predictor of major bleeding, stroke and mortality in the ARISTOTLE trial (the Apixaban for Reduction in Stroke and Other Thromboembolic Events in Atrial Fibrillation) and RE-LY (Randomized Evaluation of Long-Term
Anticoagulant Therapy), and is one of the strongest prognostic factors in the ABC (age, biomarkers, comorbidities) score, the new score for assessing risk of AF patients [22, 23].

The diagnosis of HF (especially HFpEF) in patients with AF remains a clinical challenge, since signs and symptoms, echocardiographic abnormalities and elevated NT-proBNP levels can be caused by both AF alone and by AF with concomitant HFpEF. Since GDF-15 has previously been shown to have diagnostic utility in HFpEF, with similarly or even more elevated levels as compared with patients with HFrEF, and seems to be less influenced by concomitant AF in patients with $\mathrm{HF}$ as shown in the present study, it could perhaps be a suitable companion marker next to NT-proBNP to diagnose the presence or absence of HFpEF in patients presenting with $\mathrm{AF}[9,24,25]$. This novel hypothesis should be further explored by studying the potential usefulness of GDF-15 and its clinical consequences. The combination of GDF-15 and NT-proBNP to distinguish AF versus HF by additionally comparing levels in patients with $\mathrm{AF}$ without $\mathrm{HF}$, as well as by comparing levels in patients with AF before and after cardioversion needs further investigation.

In clinical practice, NP levels are often used for therapy guidance, but these levels can fluctuate in patients with HF and paroxysmal AF, depending on whether they are in SR or $\mathrm{AF}$ at the time of measurement $[26,27]$. Since NT-proBNP is mainly produced and secreted by the cardiomyocytes in the atria and ventricles in response to haemodynamic wall stress, this marker is known to be sensitive to heart rate and rhythm disturbances [5, 7].

As described previously, most contemporary clinical HF trials use different NP thresholds for the inclusion of patients with and without AF [28-30]. These higher thresholds in patients with AF increase the probability that these patients have actual underlying HF, instead of including patients who have merely $\mathrm{AF}$ - a distinction that is especially challenging in patients with HFpEF and AF [31]. For patients with a history of AF but who are in SR at time of blood collection, 


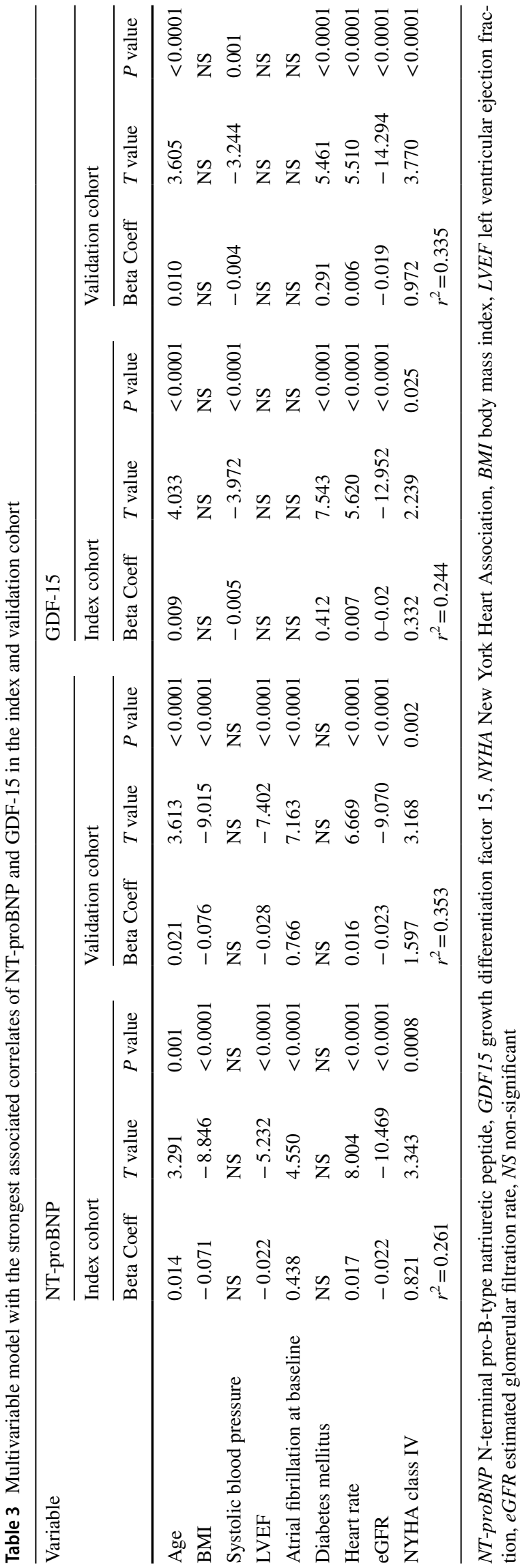

it is often unclear which threshold to use. This study shows for the first time that patients with a history of AF but who have SR at the time of measurement, have NT-proBNP levels that are much lower and more similar to those patients who have never had AF before, as compared to patients who have $\mathrm{AF}$ at time of measurement. Using a higher NP threshold for patients in SR but with a history of AF could result in inappropriately high screen failure rates in clinical trials. In these clinical HF trials, GDF-15 might be considered as an additional marker to distinguish severity of HF apart from AF.

\section{Limitations}

Limitations of this study include the post hoc design. There was a lack of information about the duration between the last episode of $\mathrm{AF}$ and screening and number/type of $\mathrm{AF}$ episodes the patient had experienced before. Asymptomatic patients with paroxysmal AF could have been missed and regarded as SR patients. Furthermore, no echocardiography data apart from LVEF was available. The NT-proBNP cutoff for inclusion in the BIOSTAT-CHF index cohort could have potentially led to higher inclusion rates of SR patients with more severe HF as compared with those with AF, and as compared with patients included in the validation cohort. However, even though this inclusion criterion differed, similar biomarker patterns were observed in both the index and validation cohort, which is a strength of the present study. Unfortunately, we were not able to further stratify the index and validation cohort in HFrEF and HFpEF, since this would have importantly limited the number of patients in the three rhythm groups within these three HF subtypes.

\section{Conclusion}

The plasma levels of NT-proBNP in HF patients were significantly influenced by the presence of $\mathrm{AF}$ at time of measurement, whereas the plasma levels of GDF-15 were independent of underlying AF. Therefore, GDF-15 might have additive value combined with NT-proBNP in the assessment of patients with $\mathrm{HF}$ and concomitant $\mathrm{AF}$.

Funding This work was supported by the Netherlands Cardiovascular Research Initiative: an initiative with support of the Dutch Heart Foundation and a grant from the European Commission [FP7-242209-BIOSTAT-CHF]. Reagents for NT-proBNP and GDF-15 were provided by Roche Diagnostics free of charge for the present study.

\section{Compliance with ethical standards}

Conflict of interest SD.A. reports grants from Vifor and Abbott Vascular, and fees for consultancy from Vifor, Bayer, Boehringer Ingelheim, Brahms, Janssen, Novartis, Servier, Stealth Peptides, and ZS Pharma. K.Di. has received honoraria and/or research support from Medtronic, 
Boston Scientific St Jude, Biotronik and Sorin, and Merck, Novartis, Amgen, Pfizer, Sanofi, Abbott and Servier. C.C.L. received consultancy fees and/or research grants from Amgen, Astra Zeneca, MSD, Novartis, and Servier. D.vV. reports board membership fees/travel expenses from Johnson \& Johnson, Novartis, Vifor, and Arca Biopharma. M.M. has received consulting honoraria from Amgen, Astra Zeneca, Novartis, Relypsa, and Servier, and speaker's fees from Abbott Vascular and Servier. A.A.V. reports consultancy fees and/or research grants from: Amgen, AstraZeneca, Bayer, Boehringer Ingelheim, Cytokinetics, GSK, Myokardia, Novartis, Roche Diagnostics and Servier. All other authors declare no conflict of interest.

Open Access This article is distributed under the terms of the Creative Commons Attribution 4.0 International License (http://creativeco mmons.org/licenses/by/4.0/), which permits unrestricted use, distribution, and reproduction in any medium, provided you give appropriate credit to the original author(s) and the source, provide a link to the Creative Commons license, and indicate if changes were made.

\section{References}

1. Maisel A, Mueller C, Adams K, Anker SD, Aspromonte N, Cleland JGF, Cohen-Solal A, Dahlstrom U, DeMaria A, Di Somma S, Filippatos GS, Fonarow GC, Jourdain P, Komajda M, Liu PP, McDonagh T, McDonald K, Mebazaa A, Nieminen MS, Peacock WF, Tubaro M, Valle R, Vanderhyden M, Yancy CW, Zannad F, Braunwald E (2008) State of the art: using natriuretic peptide levels in clinical practice. Eur J Heart Fail. https://doi.org/10.1016/j. ejheart.2008.07.014

2. van Veldhuisen DJ, Linssen GCM, Jaarsma T, van Gilst WH, Hoes AW, Tijssen JGP, Paulus WJ, Voors AA, Hillege HL (2013) B-type natriuretic peptide and prognosis in heart failure patients with preserved and reduced ejection fraction. J Am Coll Cardiol. https://doi.org/10.1016/j.jacc.2012.12.044

3. Maisel AS, Krishnaswamy P, Nowak RM, McCord J, Hollander JE, Duc P, Omland T, Storrow AB, Abraham WT, Wu AHB, Clopton P, Steg PG, Westheim A, Knudsen CW, Perez A, Kazanegra R, Herrmann HC, McCullough PA, Breathing Not Properly Multinational Study Investigators (2002) Rapid measurement of B-type natriuretic peptide in the emergency diagnosis of heart failure. N Engl J Med. https://doi.org/10.1056/NEJMoa020233

4. Kotecha D, Lam CS, Van Veldhuisen DJ, Van Gelder IC, Voors AA, Rienstra M (2016) Heart failure with preserved ejection fraction and atrial fibrillation: vicious twins. J Am Coll Cardiol 68:2217-2228

5. Rienstra M, Van Gelder IC, Van den Berg MP, Boomsma F, Van Veldhuisen DJ (2006) Natriuretic peptides in patients with atrial fibrillation and advanced chronic heart failure: determinants and prognostic value of (NT-)ANP and (NT-pro)BNP. Europace 8:482-487

6. Ellinor PT, Low AF, Patton KK, Shea MA, Macrae CA (2005) Discordant atrial natriuretic peptide and brain natriuretic peptide levels in lone atrial fibrillation. J Am Coll Cardiol 45:82-86

7. Sramko M, Wichterle D, Melenovsky V, Franekova J, Clemens M, Fukunaga M, Kautzner J (2019) Independent effect of atrial fibrillation on natriuretic peptide release. Clin Res Cardiol. https ://doi.org/10.1007/s00392-018-1332-1

8. Wang TJ, Wollert KC, Larson MG, Coglianese E, McCabe EL, Cheng S, Ho JE, Fradley MG, Ghorbani A, Xanthakis V, Kempf T, Benjamin EJ, Levy D, Vasan RS, Januzzi JL (2012) Prognostic utility of novel biomarkers of cardiovascular stress: the Framingham Heart Study. Circulation. 126:1596-1604
9. Chan MM, Santhanakrishnan R, Chong JP, Chen Z, Tai BC, Liew OW, Ng TP, Ling LH, Sim D, Leong KT, Yeo PS, Ong HY, Jaufeerally F, Wong RC, Chai P, Low AF, Richards AM, Lam CS (2016) Growth differentiation factor 15 in heart failure with preserved vs reduced ejection fraction. Eur J Heart Fail. https://doi. org/10.1002/ejhf.431

10. Kempf T, von Haehling S, Peter T, Allhoff T, Cicoira M, Doehner W, Ponikowski P, Filippatos GS, Rozentryt P, Drexler H, Anker SD, Wollert KC (2007) Prognostic utility of growth differentiation factor-15 in patients with chronic heart failure. J Am Coll Cardiol 50:1054-1060

11. Cotter G, Voors AA, Prescott MF, Felker GM, Filippatos G, Greenberg BH, Pang PS, Ponikowski P, Milo O, Hua TA, Qian M, Severin TM, Teerlink JR, Metra M, Davison BA (2015) Growth differentiation factor 15 (GDF-15) in patients admitted for acute heart failure: results from the RELAX-AHF study. Eur J Heart Fail. https://doi.org/10.1002/ejhf.331

12. Kempf T, Eden M, Strelau J, Naguib M, Willenbockel C, Tongers J, Heineke J, Kotlarz D, Xu J, Molkentin JD, Niessen HW, Drexler $\mathrm{H}$, Wollert KC (2006) The transforming growth factor-beta superfamily member growth-differentiation factor- 15 protects the heart from ischemia/reperfusion injury. Circ Res 98:351-360

13. Lok SI, Winkens B, Goldschmeding R, van Geffen AJ, Nous FM, van Kuik J, van der Weide P, Klopping C, Kirkels JH, Lahpor JR, Doevendans PA, de Jonge N, de Weger RA (2012) Circulating growth differentiation factor- 15 correlates with myocardial fibrosis in patients with non-ischaemic dilated cardiomyopathy and decreases rapidly after left ventricular assist device support. Eur J Heart Fail. https://doi.org/10.1093/eurjhf/hfs120

14. Wollert KC, Kempf T (2012) GDF-15 in heart failure: providing insight into end-organ dysfunction and its recovery? Eur J Heart Fail. https://doi.org/10.1093/eurjhf/hfs158

15. Voors AA, Anker SD, Cleland JG, Dickstein K, Filippatos G, van der Harst P, Hillege HL, Lang CC, Ter Maaten JM, Ng L, Ponikowski P, Samani NJ, van Veldhuisen DJ, Zannad F, Zwinderman AH, Metra M (2016) A systems BIOlogy Study to TAilored Treatment in Chronic Heart Failure: rationale, design, and baseline characteristics of BIOSTAT-CHF. Eur J Heart Fail. https://doi. org/10.1002/ejhf.531

16. Mordi IR, Santema BT, Kloosterman M, Choy AM, Rienstra M, van Gelder I, Anker SD, Cleland JG, Dickstein K, Filippatos G, van der Harst P, Hillege HL, Metra M, Ng LL, Ouwerkerk W, Ponikowski P, Samani NJ, van Veldhuisen DJ, Zwinderman AH, Zannad F, Voors AA, Lang CC (2019) Prognostic significance of changes in heart rate following uptitration of beta-blockers in patients with sub-optimally treated heart failure with reduced ejection fraction in sinus rhythm versus atrial fibrillation. Clin Res Cardiol. https://doi.org/10.1007/s00392-018-1409-x

17. Roche-NT-proBNP. In: . http://www.rochecanada.com/content/ dam/roche_canada/en_CA/documents/package_inserts/ProBNPII04842464190-EN-V9-CAN.pdf

18. Roche-GDF-15. In: . https://pim-eservices.roche.com/eLD_SF/ $\mathrm{gb} / \mathrm{en} /$ Documents/GetDocument?documentId=f1b11d65-4888e711-fbba-00215a9b3428

19. Du W, Piek A, Schouten EM, van de Kolk CWA, Mueller C, Mebazaa A, Voors AA, de Boer RA, Sillje HHW (2018) Plasma levels of heart failure biomarkers are primarily a reflection of extracardiac production. Theranostics. https://doi.org/10.7150/ thno. 26055

20. Bouabdallaoui N, Claggett B, Zile MR, McMurray JJV, O'Meara E, Packer M, Prescott MF, Swedberg K, Solomon SD, Rouleau JL, PARADIGM-HF Investigators and Committees (2018) Growth differentiation factor-15 is not modified by sacubitril/valsartan and is an independent marker of risk in patients with heart failure and reduced ejection fraction: the PARADIGM-HF trial. Eur J Heart Fail. https://doi.org/10.1002/ejhf.1301 
21. Wollert KC, Kempf T, Wallentin L (2017) Growth differentiation factor 15 as a biomarker in cardiovascular disease. Clin Chem. https://doi.org/10.1373/clinchem.2016.255174

22. Hijazi Z, Oldgren J, Lindback J, Alexander JH, Connolly SJ, Eikelboom JW, Ezekowitz MD, Held C, Hylek EM, Lopes RD, Siegbahn A, Yusuf S, Granger CB, Wallentin L, ARISTOTLE and RE-LY Investigators (2016) The novel biomarker-based ABC (age, biomarkers, clinical history)-bleeding risk score for patients with atrial fibrillation: a derivation and validation study. Lancet 387:2302-2311

23. Hijazi Z, Oldgren J, Lindback J, Alexander JH, Connolly SJ, Eikelboom JW, Ezekowitz MD, Held C, Hylek EM, Lopes RD, Yusuf S, Granger CB, Siegbahn A, Wallentin L, ARISTOTLE and RE-LY Investigators (2018) A biomarker-based risk score to predict death in patients with atrial fibrillation: the ABC (age, biomarkers, clinical history) death risk score. Eur Heart J. https ://doi.org/10.1093/eurheartj/ehx584

24. Santhanakrishnan R, Chong JP, Ng TP, Ling LH, Sim D, Leong KT, Yeo PS, Ong HY, Jaufeerally F, Wong R, Chai P, Low AF, Richards AM, Lam CS (2012) Growth differentiation factor 15, ST2, high-sensitivity troponin $\mathrm{T}$, and $\mathrm{N}$-terminal pro brain natriuretic peptide in heart failure with preserved vs. reduced ejection fraction. Eur J Heart Fail. https://doi.org/10.1093/eurjhf/hfs130

25. Stahrenberg R, Edelmann F, Mende M, Kockskamper A, Dungen HD, Luers C, Binder L, Herrmann-Lingen C, Gelbrich G, Hasenfuss G, Pieske B, Wachter R (2010) The novel biomarker growth differentiation factor 15 in heart failure with normal ejection fraction. Eur J Heart Fail. https://doi.org/10.1093/eurjhf/hfq151

26. Lainchbury JG, Troughton RW, Strangman KM, Frampton CM, Pilbrow A, Yandle TG, Hamid AK, Nicholls MG, Richards AM (2009) N-terminal pro-B-type natriuretic peptide-guided treatment for chronic heart failure: results from the BATTLESCARRED
(NT-proBNP-Assisted Treatment To Lessen Serial Cardiac Readmissions and Death) trial. J Am Coll Cardiol. https://doi. org/10.1016/j.jacc.2009.02.095

27. Felker GM, Hasselblad V, Hernandez AF, O'Connor CM (2009) Biomarker-guided therapy in chronic heart failure: a meta-analysis of randomized controlled trials. Am Heart J. https://doi. org/10.1016/j.ahj.2009.06.018

28. Armstrong PW, Roessig L, Patel MJ, Anstrom KJ, Butler J, Voors AA, Lam CSP, Ponikowski P, Temple T, Pieske B, Ezekowitz J, Hernandez AF, Koglin J, O'Connor CM (2018) A multicenter, randomized, double-blind, placebo-controlled trial of the efficacy and safety of the oral soluble guanylate cyclase stimulator: the VICTORIA trial. JACC Heart Fail 6:96-104

29. Solomon SD, Rizkala AR, Gong J, Wang W, Anand IS, Ge J, Lam CSP, Maggioni AP, Martinez F, Packer M, Pfeffer MA, Pieske B, Redfield MM, Rouleau JL, Van Veldhuisen DJ, Zannad F, Zile MR, Desai AS, Shi VC, Lefkowitz MP, McMurray JJV (2017) Angiotensin receptor neprilysin inhibition in heart failure with preserved ejection fraction: rationale and design of the PARAGON-HF trial. JACC Heart Fail 5:471-482

30. Teerlink JR, Felker GM, McMurray JJ, Solomon SD, Adams KF, Cleland JG, Ezekowitz JA, Goudev A, Macdonald P, Metra M, Mitrovic V, Ponikowski P, Serpytis P, Spinar J, Tomcsanyi J, Vandekerckhove HJ, Voors AA, Monsalvo ML, Johnston J, Malik FI, Honarpour N, COSMIC-HF Investigators (2016) Chronic Oral Study of Myosin Activation to Increase Contractility in Heart Failure (COSMIC-HF): a phase 2, pharmacokinetic, randomised, placebo-controlled trial. Lancet 388:2895-2903

31. Kelly JP, Mentz RJ, Mebazaa A, Voors AA, Butler J, Roessig L, Fiuzat M, Zannad F, Pitt B, O’Connor CM, Lam CSP (2015) Patient selection in heart failure with preserved ejection fraction clinical trials. J Am Coll Cardiol. 65:1668-1682 